\title{
Chapter 7 \\ Flanders: Regional Organization of Water and Drought and Using Data as Driver for Change
}

\author{
Jenny Tröltzsch, Rodrigo Vidaurre, Hans Bressers, Alison Browne, \\ Isabelle La Jeunesse, Maia Lordkipanidze, Willem Defloor, \\ Willem Maetens and Kris Cauwenberghs
}

\subsection{Introduction}

This chapter presents a summary of the analysis results of the governance of drought-related issues in the Flanders region of Belgium. In the context of the Interreg IV-B project DROP, a team of researchers from four universities and knowledge institutes visited Flanders twice to perform interviews with authorities and stakeholders (October 2013 and May 2014). The visit was supported by colleagues at the Flemish Environment Agency (Vlaamse Milieumaatschappij, VMM). The exchange was held in the form of individual and group interviews and workshops with stakeholders including representatives from different institutions and sectors, e.g. from the drinking water company, national and local nature protection organizations, local farmers and local and national farmers organizations, the Flemish Environment Agency, different provinces, e.g. Province Vlaams-Brabant, and local municipalities, e.g. Kortemark Municipality. The analysis was guided by the drought-related Governance Assessment Tool (GAT) developed for the project. The GAT contains five governance dimensions (levels and scales, actors and networks, problem perceptions and goal ambitions, strategies and instruments, responsibilities and resources) and four governance

J. Tröltzsch $(\bowtie) \cdot R$. Vidaurre

Ecologic Institute, Pfalzburger Strasse 43/44, 10717 Berlin, Germany

H. Bressers · M. Lordkipanidze

University of Twente, PO Box 7658, 8903 JR Leeuwarden, The Netherlands
A. Browne
University of Manchester, Manchester M13 9PL, UK
I. La Jeunesse
University Francois Rabelais, Tours, France
W. Defloor · W. Maetens · K. Cauwenberghs
Vlaamse Milieumaatschappij, Aalst, Belgium
(C) The Author(s) 2016
H. Bressers et al. (eds.), Governance for Drought Resilience,
DOI 10.1007/978-3-319-29671-5_7 


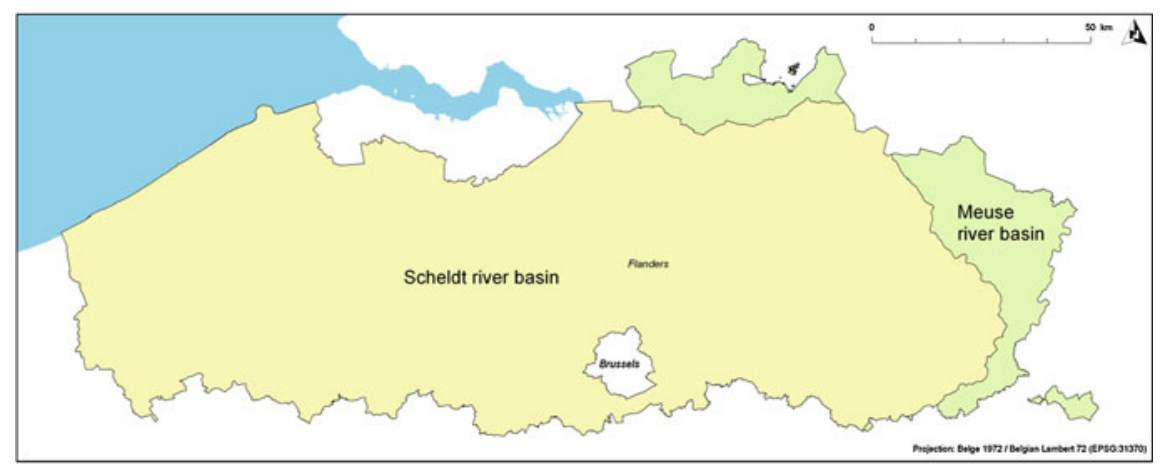

Fig. 7.1 Map of Flanders, with its territory's distribution over the two river basins Scheldt and Meuse (Source VMM)

criteria (extent, coherence, flexibility and intensity). The methodology is described in detail in Chap. 3.

The chapter presents the context of water management in Flanders, describes some measures which are already implemented related to drought management, explains the results of our analysis in terms of the Governance Assessment Toolkit and presents our possible conclusions and recommendations for improved drought governance.

According to the definition of the Water Framework Directive (WFD), the Belgian territory belongs to four international river basin districts (RBDs) which are shared with other member states and/or third countries. The RBDs of Meuse and Scheldt cover most of the Belgian territory, whereas the Rhine and Seine river basins cover much smaller parts in the south of Belgium.

Figure 7.1 shows that the Flemish region is located predominantly within the Scheldt river basin district. A comparatively small fraction of Flanders lies within the Meuse river basin district.

The Flemish region is divided over four river basins: Scheldt, Meuse, Ijzer and Polders of Bruges. Ijzer and Polders of Bruges are two comparatively small coastal catchments, added to the (International) WFD Scheldt River Basin District. The Flemish region covers $13.521 \mathrm{~km}^{2}$ and has a population of 6.35 million inhabitants. The Scheldt (466 inh. $/ \mathrm{km}^{2}$ ) and the Meuse (258 inh. $/ \mathrm{km}^{2}$ ) river basin districts show a very high population density.

Contrary to the other chapters based on the DROP case studies, this chapter covers Flanders as an entire region. This choice was made due to the importance of federalism in Belgium and the more centralized approach compared to other chapters which are focusing on a specific catchment. 


\subsection{The Regional Organization of Drought Management: Flemish Water Management}

\subsubsection{Water Management in Flanders}

Belgium is a federal state with responsibilities for water management at the regional and the federal level. The federal and regional competences are exclusive and equivalent, with no hierarchy between the standards issued by each. The Federal Government has amongst other things environmental responsibilities for coastal and territorial waters (from the lowest low-waterline). The Regions are responsible in their territory for environment and water policy (including technical regulations regarding drinking water quality, responsibility for the economic aspects of drinking water provision, land development, nature conservation and public works and transport. With the exception of the Federal Plan on Coastal Waters, water management plans are developed at the regional level, and therefore a mainly regional approach to river basin planning is used in Belgium. Coordination of water management planning occurs at the national and European level.

At the regional level in Flanders, three Flemish ministries are involved in integrated water policy: the Ministry of the Environment and Nature, the Ministry of Mobility and the Ministry of Spatial Planning. Many tasks related to integrated water management are assigned to the Flemish Environment Agency (VMM).

For the organization and planning of integrated water management, the Decree on Integrated Water Policy (of 2003) distinguishes three levels:

- The two International River Basin Districts (Scheldt and Meuse).

- The Flemish region with its four river basins (Scheldt, Ijzer, Polders of Bruges, Meuse - of which IJzer and Bruges Polder are added to the Scheldt).

- The 11 sub-basins.

This Decree is the juridical implementation of the WFD. However, it incorporates even more policy items of integrated water policy than those legally required by the WFD, prescribing more detailed planning on the level of sub-basins, as well as integrating quantitative aspects and the relation with spatial planning. It also contains the juridical implementation of the Floods Directive.

The responsibility for drawing up river basin management plans for the two Flemish parts of the international river basin districts Scheldt and Meuse lies with the Flemish government. The Coordination Committee on Integrated Water Policy (CIW; chaired by VMM) is designated as the competent authority for the implementation of the WFD, as well as for the Floods Directive. Among its responsibilities are the preparation of the River Basin Management Plans (RBMPs), including the sub-basin parts and groundwater specific parts, for the Flemish Region, reporting to the European Commission on WFD implementation, organizing the public consultation of the RBMPs, preparing the methodology and guidance for the development of the RBMPs and aligning the RBMPs with the Flemish Water Policy Note. The CIW consists of the executive management of the 


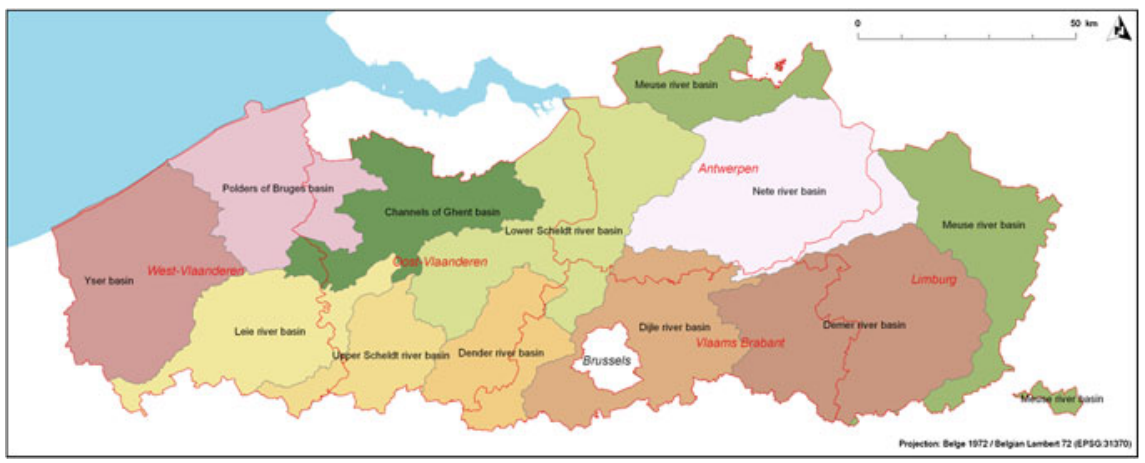

Fig. 7.2 Overview of sub-basins (11) in Flanders. In red are shown the limits of the Flanders' provinces (Source VMM)

administrative entities involved in water management. The CIW also oversees the functioning of the sub-basin structures, providing support and reviewing possible contradictions between binding provisions of the management plans at the different levels.

Figure 7.2 provides an overview of Flanders' eleven sub-basins, as well as the borders of the five Flanders provinces.

The international Meuse River Basin extends over five Member States of the European Union (France, Belgium, Netherlands, Germany and Luxembourg), and covers all three of the Belgian regions (Flanders, Wallonia and Brussels). The multilateral coordination in the international river basin district (IRBD) Meuse falls under the Meuse Treaty, ${ }^{1}$ which regulates, among others, the international coordination of the implementation of the WFD in the IRBD Meuse. Further bilateral consultations are in place for the Netherlands and the Walloon Region.

In addition to these multilateral and bilateral consultations there is also intra-Belgian coordination for which the Coordination Committee for International Environmental Policy (CCIM) is used. This cooperation agreement is legally binding for the government after it was ratified by each government through law, decree or ordinance.

\subsubsection{Evolution of Flanders' Water Policy}

Starting in the early 1970s, Belgium started to progressively evolve towards federalism, becoming a fully federal state in 1993. In the field of water, the

\footnotetext{
${ }^{1}$ The Meuse Treaty was concluded in 2002 in Ghent between the governments of France, the federal state of Belgium, the Walloon Region, the Flemish Region, the Brussels Capital Region, the Netherlands, Germany and Luxembourg.
} 
competencies for water quality aspects were transferred to the Regions in 1980, and the same occurred in 1990 for the quantity aspects.

The Region of Flanders' initial approach to water management was the implementation of the 1971 ('federal') law on the protection of surface and groundwater against pollution (Bressers and Kuks 2004). In 2003 the Integrated Water Decree was passed in Parliament. The WFD is transposed with the coming into effect of the Integrated Water Decree. River basin management planning is an important part of the Decree.

The Integrated Water Decree applies to the water systems which are situated in the Flemish Region. Water systems are defined as 'a coherent and functional entity of surface water, groundwater, water beds and banks, including all living communities therein with all physical, chemical and biological processes thereof, and the corresponding technical infrastructure' (CIW 2003). Thus, the scope of the Flemish Decree covers surface waters and groundwater, as well as infrastructure such as bridges, dikes, locks and dams. Furthermore, the Decree contains regulations on water quality management as well as on water quantity management. In 2010, the implementation of the European Flood Directive was integrated in the Decree.

In accordance with the Decree, one minister in the Flemish Government is appointed to be responsible for the coordination and organization of the integrated water policy. He will be assisted by the CIW chaired by VMM. This multi-disciplinary commission unites different levels of water management and governance. It is responsible for the preparation, planning and the monitoring of integrated water policy, and it is responsible for the implementation of the decisions on integrated water policy of the Flemish government. The CIW also watches over the uniform approach to the management of each basin.

The First Flemish Water Policy Note was prepared by CIW in 2005 and presents the Flemish Vision on water policy (CIW 2005). The vision was updated in 2013 with the Second Flemish Water Policy Note (CIW 2013). This document holds the goals of the Flemish government with regard to water management for the years 2014-2021. It names as its main goal the financing and implementation of integrated water management principles. It organizes the five current water management tasks in a framework of six guiding notions:

(1) Better protection and improvement of the quality of the water system: Corresponding water management tasks: (1) the restoration of the good environmental status of the surface water and (2) the chemical water quality of groundwater resources require additional effort.

(2) Sustainable management of water resources and ensuring sustainable water supply: Corresponding water management task: (3) the water use requires further actions for improving water use quantity.

(3) Integrated management of water scarcity and flooding: Corresponding water management task: (4) the damage caused by water scarcity and flooding needs to be minimized further. 
(4) Further development of the vision to financing water management: Corresponding water management task: (5) Big challenges will have to be coped with limited means.

(5) Further stimulation of multifunctional use of water

(6) Working together on a strong and coordinated water management.

\subsection{The Flemish Geo-hydrological Context: Using Data for Cooperation}

\subsubsection{Drought in the Context of Water Management in Flanders}

In Flanders, pressure on water resources is high, which is amongst others due to the high population density. Water managers have historically paid much attention to guaranteeing water supply and water quality and mitigating the risk of flooding. Nevertheless, drought and water scarcity resulting from drought, are well known problems in specific sectors relying on a good water supply, such as agriculture.

In the past, Flanders, as most European regions, has experienced droughts in the years 1976, 1996, 2003, 2006 and 2011 [for further information see Chap. 6 ]. In recent years, droughts have had several consequences in Flanders. On some occasions water extraction from the Albertkanaal has been restricted. The 1996, 2006 and 2011 droughts were recognized as agricultural disasters and affected farmers were financially compensated. Temporary restrictions have been placed on the draft of ships on the Meuse river and in 2003 also on the use of the locks. Furthermore, Flanders experienced also other problems related to droughts; due to the wildfire in the nature reserve Kalmthoutse Heide in 2011, about 600 ha of heathland has been burned.

Drought policy in Flanders is based on the implementation of the European guidelines laid out in the WFD (EC 2000), resource efficiency policy (EC 2011), Blueprint to Safeguard Europe's Water Resources (EC 2012) and the Communication on drought and water scarcity (EC 2007). The management of water resources in Flanders, and hence the implementation of measures concerning drought and water scarcity, is delegated to a number of water managers with specific competences. The Division of Operational Water Management of the VMM is competent for the management of about $1,400 \mathrm{~km}$ of the larger unnavigable watercourses. As part of the DROP project, the VMM pilot is focussed on the improvement of drought risk management and the improvement of knowledge and data collection, which were listed as policy options in the European Commission's Communication on drought and water scarcity (EC 2007). 


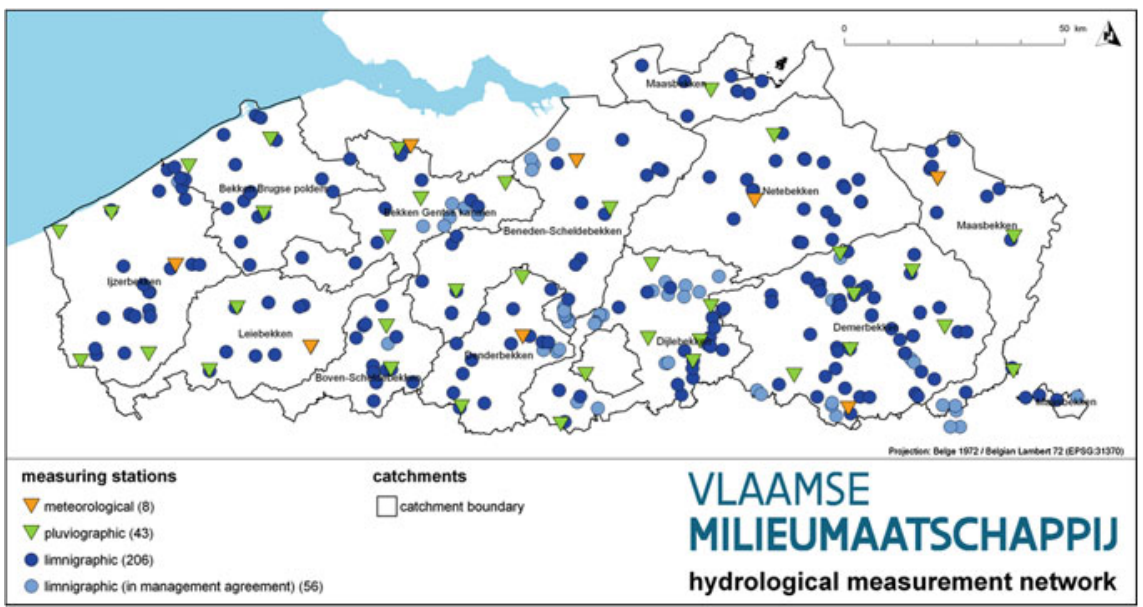

Fig. 7.3 Hydrological measurement network in Flanders (Belgium) operated by the VMM (Source VMM)

\subsubsection{To Measure Is to Know: A Framework for Drought Monitoring and Modelling}

VMM operates a dense hydrological measurement network to monitor precipitation, evapotranspiration, river stage and discharge in Flanders (Fig. 7.3). Real-time measurements from these stations are used for monitoring the water system, flood forecasting and operating the water infrastructure in Flanders.

In the DROP project, six water boards and water authorities implemented and tested innovative concrete measures focusing on specific drought and water scarcity problems as pilots. The aim of VMM's DROP pilot case was the development and use of indicators for the monitoring and reporting of the drought situation and the modelling of drought impacts using this measurement network. Also, further needs for the expansion of the network to make it better suited for drought applications such as drought monitoring, forecasting and the evaluation of drought measures, were outlined.

Droughts are complex phenomena, and are usually divided into four cascading levels: megadroughts; meteorological drought, resulting from a lack of rainfall; agricultural and ecological drought, resulting mainly from a lack of soil moisture; and hydrological drought, resulting from a lack of river flow. For the three levels: meteorological, agricultural and ecological drought, and hydrological drought, specific indicators were set up: meteorological drought is quantified by the Standardized Precipitation Index (SPI; McKee et al. 1993; Fig. 7.4) and Precipitation Deficit, agricultural and ecological drought by soil saturation, and hydrological drought by flow exceedance percentiles and the Standardized Streamflow Index 


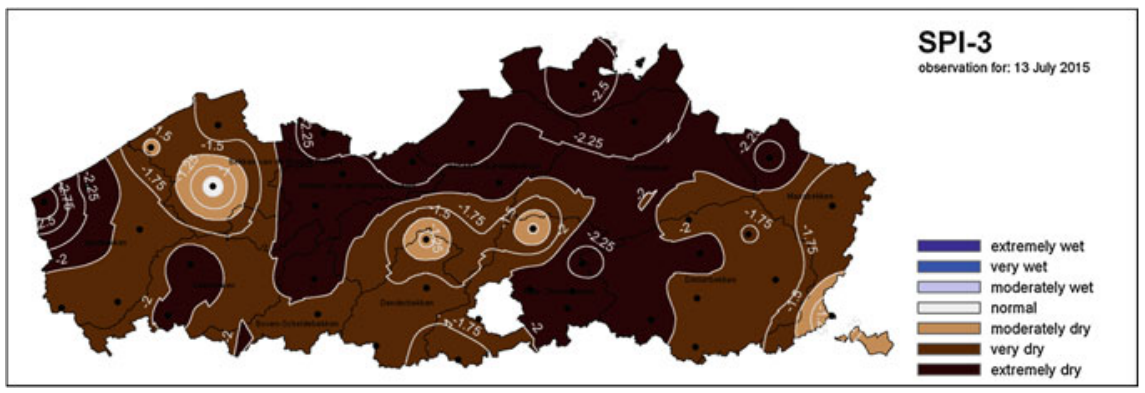

Fig. 7.4 Spatial distribution of the SPI-3 in Flanders on 13 July 2015 during a dry spell in summer (Source VMM)

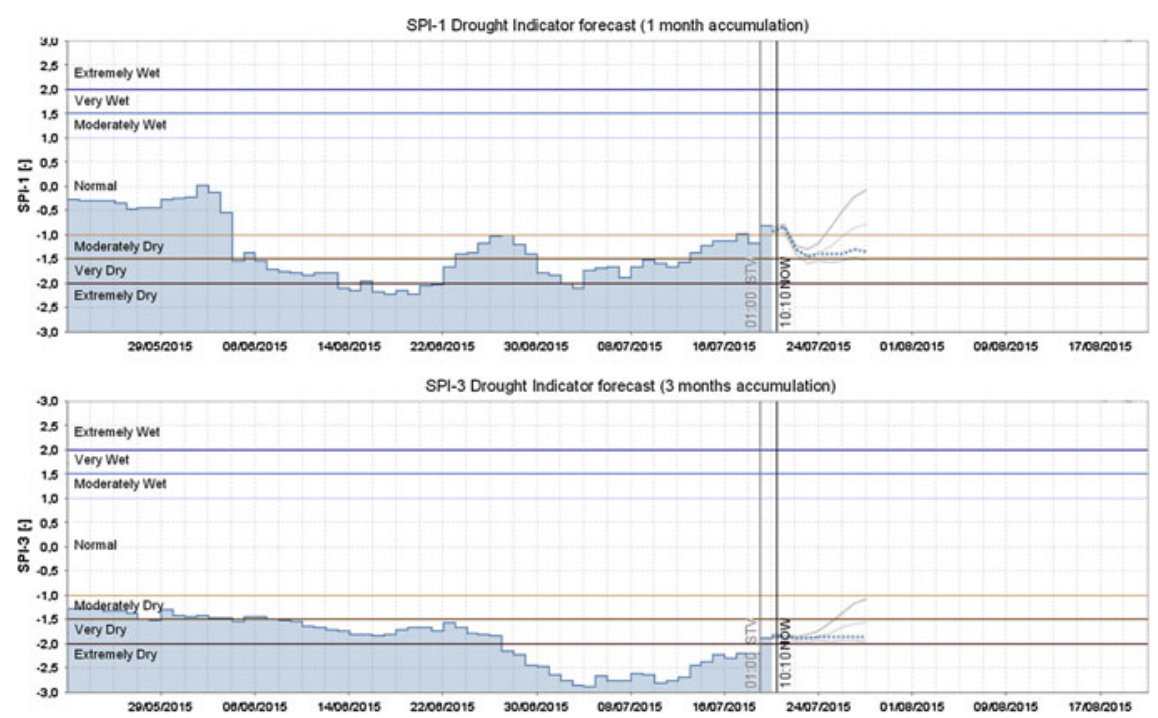

Fig. 7.5 Evolution of the SPI-1 (upper graph) and SPI-3 (lower graph) in the spring and summer of 2015 at the VMM pluviometric station at Boekhoute, with a 10-day deterministic forecast (blue dotted line) and probabilistic forecast (grey lines represent the 10th, 25th, 75th and 90th percentile of probabilistic forecasts) (Source VMM)

(SSI; Vicente-Serrano et al. 2011). Where possible, also a 10-day forecast for these indicators was developed to allow proactive management (Fig. 7.5).

To translate observations to impacts, modelling tools were developed. These models allow assessing the impact of past droughts (for a better understanding of drought impacts), present droughts (for operational drought management) as well as expected future droughts (in support of drought adaptation measures) on different aspects of the water system (e.g. soil moisture, streamflow) and on agricultural production (yield loss). In two pilot catchments spatially distributed SWAT (Soil and Water Assessment Tool, Arnold et al. 1998) water balance models and SWAP 
(Soil-Water-Atmosphere-Plant) 1-dimensional soil moisture models were implemented. Through these models, the effect of soil and crop type, and drought severity and time of occurrence during the year on the eventual impacts of the drought can be highlighted. Further development of these models and expanding the modelled area can support the development of drought adaptation and mitigation policy in Flanders.

During the development of drought indicators and models for Flanders, a data and information gap concerning soil moisture, a key variable in drought monitoring and impact assessment, became apparent. Therefore, a soil moisture measuring campaign was set up, in which 15 traditional soil moisture probes and two innovative area-integrated soil moisture probes (COsmic-ray Soil Moisture Observing System; Zreda et al. 2012) were installed in the modelled catchments. In addition, the use of the Soil Water Index (SWI; COPERNICUS 2015) based on remotely sensed soil moisture data was tested in combination with ground measurements. The results of this study were used in the development of a Flemish soil moisture network, for which the probes will be relocated to locations distributed throughout Flanders to assure an optimal assessment of soil moisture conditions throughout the region in combination with satellite imagery.

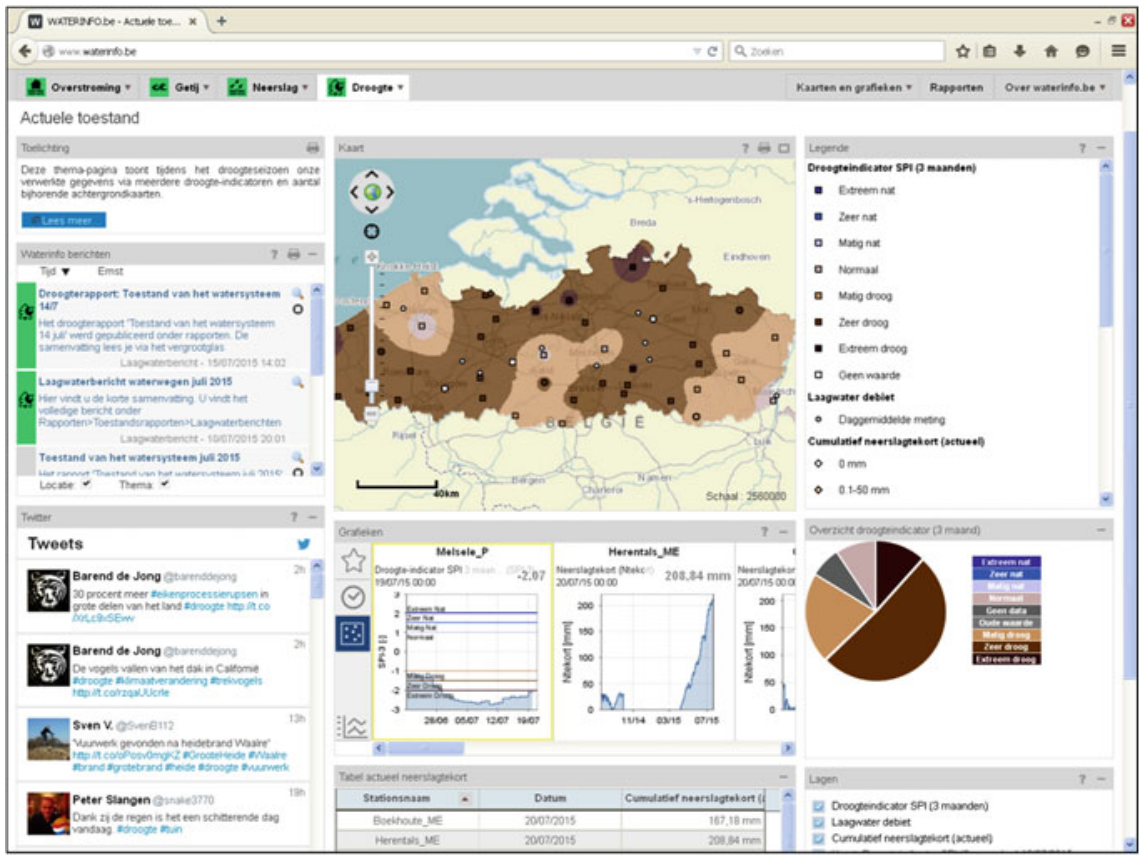

Fig. 7.6 www.waterinfo.be acts as a common portal for five Flemish water managers to report the state of the water system and focusses, depending on the situation, on floods, tides, precipitation or droughts (displayed here) (Source VMM) 


\subsubsection{Turning Data into Information and Cooperation}

A further key step towards effective drought management is turning these data into useful information and getting the information to the different actors and stakeholders. Therefore, VMM publishes a monthly bulletin on the state of the water system, focusing on drought or flood risks as required. Since 2014, five Flemish water management services bundle their efforts to make real-time data and forecasts on the state of the water system available through the web portal www.waterinfo.be (Fig. 7.6). Drought is included as one of the four main themes of the portal. Information on the drought situation can be used by actors such as decision makers or water managers, or individual stakeholders, such as farmers, to evaluate the drought situation and take action accordingly.

It has been found that relying on the existing measuring network and framework of data management and reporting at VMM, contributes to a more effective drought status reporting. It also represents a technical step towards the development of an integrated water management strategy that addresses both high flows (floods) and low flows (hydrological droughts).

At the same time, the VMM pilot participated actively in the creation of a coordination platform for drought by bringing together different governmental agencies and organizations involved in water management and agriculture. This will further stimulate the cooperation between different actors and stakeholders on drought issues, such as the Flemish agricultural department, regional and national water managers, the provinces and municipalities.

\subsection{Governance Assessment: Improvements in Drought Awareness but not There yet}

In the following section, the four qualities of the GAT-tool presented in Chap. 3 are analysed for the Flanders region. Contrary to the other DROP case studies the GAT-tool was used here for the assessment of a whole region and not only a single catchment. Furthermore, the national level in Belgium has transferred most responsibilities to the regional levels: Wallonia, Brussels and Flanders. Because of the entry point at a relative high scale, one difficulty was to also cover small, individual activities on local level. Additionally, the relationships between different authorities and ministries were central in the discussions.

\subsubsection{Extent}

In terms of extent, the general water management system in Flanders is assessed as supportive with good involvement of EU level, Flemish region, provinces, 
communities and municipalities, as well as strong interactions between different actors and networks. The fact that the national (Belgian) level is receding to mainly a coordinating role is not considered to be a problem. The Flemish level is the key agent in generating initiatives and policy. However, there is a negative trend in which municipalities seem to be disengaging from water management responsibilities, for instance in their handing over responsibilities for "type 3" (small) watercourses to the provinces. This could mean that municipalities end up 'out of the loop' regarding, for example, water quality and nature protection, and thus may be unaware of opportunities for synergies related to water management, such as drought preparedness. This is problematic as they keep the responsibility for flood measures, and measures to dovetail drought prevention while addressing flood, may not be incorporated as they could. This is also relevant when considering that groundwater permits are given by towns and municipalities. This being said, interviewed stakeholders tended not to see this change as a problem.

Specifically in drought terms, extent is more limited, as initiatives are restricted to the higher levels, i.e. policy visions and planning initiatives for Flanders. The fact that recent European directives such as the Floods Directive, have a broader perspective which includes social and ecological criteria, has recently expanded the extent of actors and networks involved in water policy. The commitment to intersectoral involvement can be seen in the CIW, which includes leading officials of agriculture, nature and planning. However, involvement of stakeholders and the public in Flemish water planning is seen by many interviewees as closer to pro forma than to the aim of shaping environmental actions. Interviewees highlighted that they are not involved in the planning phase of policy, such as in the selection and prioritization of measures to be implemented, but only in the implementation phase itself. The wish to be involved earlier in the planning process was expressed clearly by several stakeholders. In addition, the lower level is not always actively participating in these processes, e.g. polders and wateringen, which are public authorities responsible for water resources management in the polder areas.

In general, drought is not yet an issue compared to the perception of flooding impacts for the region. The awareness of water scarcity and drought problems is very low for some stakeholders. Drought resilience, as a topic, is weakly developed in current constellations of problems and goals defined by stakeholders in the region. Various problem perspectives, e.g. from farmers, nature organizations, drinking water availability, are being taken into account in discussions, but there is as yet not much work on prioritization of drought and water scarcity as an issue.

In terms of instruments, different instruments are already implemented, such as groundwater taxes for business users (handpumps and households not included), groundwater permits, and restrictions for water extraction. Furthermore, important strategies integrate water scarcity and water demand, e.g. the 'Flemish vision on water policy' from 2005 to 2013 includes the sustainable use of water, and states that it is necessary to deal coherently with water shortage (CIW 2005, 2013). It has been agreed that the second River Basin Management Plans (due in 2015) should also include measures for water scarcity and droughts. In addition, the Environmental Policy Plan 2011-2015 'MINA-Plan 4' mentions as objective: 
groundwater quantity and water use (Vlaamse overheid 2011). But a key missing instrument seems to be the agreement regarding flows over the border with France for the Scheldt river, and the lack of agreements regarding transboundary groundwater bodies. There is also significant potential for 'mainstreaming' drought into existing measures to make them serve multiple objectives. In particular, it would seem that flood prevention infrastructure (often small-scale dams) can be managed in a way that incorporates drought considerations. Otherwise, Flanders shows quite a significant number of instruments in place, particularly for groundwater management. However, with VMM which is the only actor developing measures, and with other stakeholders not having the issue of drought on their agendas, there does not seem to be a positive extent to the responsibilities and resources assigned. The level of involvement in planning is seen as insufficient by some stakeholders, who regret that they are not consulted in the planning phase of policy (measure selection and prioritization), but only when it comes to implementation questions.

\subsubsection{Coherence}

Coherence seems to be mildly supportive in the Flemish context, but this evaluation is mainly dependent on the direction of further activities. Whereas there are as yet not many actions that address droughts at the Flanders level, there seems to be a 'culture of coordination' within the authorities dealing with water topics, and other existing frameworks seem to be geared towards coherence. At the Belgian level, there are different coordination committees, but also institutional arrangements, such as the CIW, which meet frequently. The coordination between different authorities at the local level with district and province levels, seems to be both intense and fruitful, and planning moves up and down levels, according to the size of initiatives. The mentioned 'culture of coordination' shows that relevant actors work well together. There are good and productive relationships in place, with regular exchange. This is partly due to the long tradition of working together, that some actors have with the Flemish region. The last few decades have also seen great improvements in the dialogues with stakeholders traditionally less involved in decision-making (e.g. nature organizations). However, some smaller actors are more distant from the processes. At the lower levels, such as municipalities, the awareness seems to be quite moderate and partially a possible mismatch of objectives occurs.

Problem perspectives could be more coherent if knowledge-based approaches for droughts, such as the DROP pilot, are used. The ORBP process for floods showed that a solid common scientific basis can increase the coherence of perceptions. A need for a more integral vision on the water conditions of other sectors was already mentioned. Some incoherencies seem to exist between the drinking water companies (which provide lower water prices for large-volume consumers) and the environmental objectives of VMM. 
Regarding instruments, the current existing instruments addressing droughts have not been developed within a strategic approach. The instruments were developed very independently for each of the different relevant areas. Because only a limited number of instruments relevant for drought purposes are in place, in general the instruments do not overlap. Smaller problems exist, e.g. between groundwater recharge and rainwater storage, which should be taken into consideration for new instruments. Over the past years, the topic of water scarcity and droughts has been integrated in several strategy papers and the Flemish vision on water. However, the future development of these issues could be helped by a more strategic approach. Further activities for a coherent approach in water management in general, can be seen in the synchronization of the planning period of sub-basin RBMPs (and basin RBMPs. Also the integration of drought measures in the RBMPs (from 2015) shows a tendency to a harmonized approach of developing and implementing drought measures with other water management measures.

The responsibilities for water scarcity and droughts are unclear or not assigned in many organizations and levels, including the Flemish regional level. Within in VMM, responsibilities are associated with different departments and therefore are very fragmented. This fragmentation leads to own individual discussions with the 'normally' involved institutions and levels. A coherent connection between the different discussions and approaches is not realized in the most involved organizations. Because the issue is not high on the agenda, there are as yet no competence conflicts between the different actors.

\subsubsection{Flexibility}

The analysis shows a moderate flexibility of the water governance system. Federal arrangements seem to point towards a good flexibility between different levels and scales, a flexibility that is built into the system: problems are dealt with 'at the relevant level', for example, in direct negotiation between Brussels and Flanders when it comes to a new waste water treatment plant. The possibility of issues moving up one level can be seen in cross-boundary management issues. However, on the topic of drought, the lead is currently firmly in the hands of VMM, and no clear possibilities of issues moving downwards, to a level closer to local, on-the-ground implementation of actions, were observed.

The high involvement of actors in the processes, with both formal and informal contacts, is positive. The formal coordination mechanisms are complemented by informal ones between different actors in water management. The fact that Flanders in a comparatively small region has all the different levels and actors ranging from a 'central government' to the local level would seem to help in the processes of VMM and others, reaching out to different actors. However, the flexibility in the kind of involvement and at what stage of the process could be increased, e.g. so that relevant actors can also be part of planning processes. 
At the moment, goals are not at the stage of being discussed within policy processes, and therefore very far from being operational. Currently, the emphasis is still on building up a knowledge base. Willingness to find flexible solutions can be noticed, and water managers do meet and develop solutions, when necessary. This flexibility is also the result of not really having any formal mechanisms in place.

An element, conducive to flexibility, is the scenario-based planning approach. Furthermore, several instruments show aspects of flexibility. The short-term permits for groundwater in problem areas, with continuous search for surface water alternatives, show high degree of flexibility in the design and implementation of measures. Furthermore, the drinking water plans for increasing infrastructure interconnectivity show a tendency towards increased flexibility, as does the drinking water companies' recognizing the need for additional buffering capacity.

The scientific approach used for the development and implementation of flood measures, was driven by VMM. The stakeholders were presented with suitable measures, which had already been derived by VMM. In our interviews, some stakeholders criticized their involvement as being too late (e.g. not participating in measure selection) and mentioned that the acceptance of the measures is not always high. Therefore, the flexibility of the approach seems to be limited because the selection and adjustment of measures by stakeholders and implementers are not a main focus.

Because there is no assigned budget for droughts, the resources have to come from different related resources, such as nature and biodiversity; these include certain flexibility. Synergies occurring with a combination of drought and flooding are yet not taken into account.

\subsubsection{Intensity}

As in the other DROP case study areas in Northwest Europe, by far the relatively weakest point of the governance context for drought resilience policies and measures is its intensity.

The EU level, which has been fundamental in providing impulse to change in water management in Flanders, is only starting to develop relevant actions for water scarcity and droughts. There is some movement at the Flanders level, with droughts being incorporated as an issue into recent policy vision documents, but this has yet to be translated into actions. At the moment, the Flemish region carries the responsibility more or less single-handedly to bring in drought aspects into water planning, which makes activities dependent on this governance level.

VMM is keen to develop some of these actions and is the main driver behind initiatives to tackle drought - the DROP project being one of them. Although there is recognition of the importance and desirability of addressing droughts, at the moment no other actors really have this topic on their agenda or are driving it. There is only one actor driving change, and the establishment and implementation of strategies and instruments is very dependent of the Flemish regional level. At the 
moment, no strong drought-related strategy exists which could initiate strong drought-related activities. But in the last year, in several important strategic policy documents on Flanders level such as 'Flemish vision on water policy' and 'MINA-Plan 4', water scarcity and drought aspects were included.

Existing goals have to be improved. It will be necessary to go beyond the policy that is already in place (business-as-usual). Further goal ambitions should also be increased, but for this the awareness of the problem of water scarcity and droughts has to be improved so new and ambitious goals are agreed on with a huge number of relevant stakeholders. At the moment, many stakeholder groups have a quite low awareness of the problem and do not intend to support goals. It is currently only possible to implement local projects where local problems are clear. Even in these situations, gaining a long-term perspective versus just solving immediate problems, it is very problematic.

However, many stakeholder groups' awareness of the problem is quite low, and while they are in favour of initiatives addressing droughts, it is not considered as one of the issues on their agendas, which means that no energy and resources are earmarked to address the topic. Awareness of problems among farmers is growing, but they still want to use groundwater resources today and do not integrate the perception of future generations in their actions. The fact that most stakeholders do not seem to be involved, seems to be a hurdle for further actions, as much depends on individual coalitions between agencies and stakeholders. These coalitions have to be built up for every individual project implementation or also for policy processes. Furthermore, instruments for awareness-raising of different stakeholders are also not clearly defined.

\subsubsection{Summary}

The analysis of the drought governance qualities leads to the conclusion that the governance context for drought resilience policies and measures in Flanders can be regarded as at the moment 'intermediate'. Overall, both extent and coherence are between moderate and supportive for most governance dimensions, with the exception of 'responsibilities and resources', which are somewhat underdeveloped but are to be expected for a new issue. Flexibility is mostly moderate, with significant room for improvement, and intensity is as yet neutral to restrictive-again something to be expected for a new water management issue. In Fig. 7.7, our findings are visualized. 


\begin{tabular}{|c|c|c|c|c|}
\hline & Governance Crit & iteria & & \\
\hline \begin{tabular}{|l} 
Governance \\
Dimensions
\end{tabular} & Extent & Coherence & Flexibility & Intensity \\
\hline Levels \& scales & & & & \\
\hline Actors \& networks & & & & \\
\hline $\begin{array}{l}\text { Problem perceptions } \\
\text { \& goal ambitions }\end{array}$ & & & & \\
\hline $\begin{array}{l}\text { Strategies \& } \\
\text { nstruments }\end{array}$ & 1 & & & \\
\hline $\begin{array}{l}\text { Responsibilities \& } \\
\text { resources }\end{array}$ & & & & \\
\hline
\end{tabular}

Fig. 7.7 Summary visualization-Governance context assessment for droughts in the Flanders region

\subsection{Improving Drought Governance in Flanders: Conclusions and Recommendations}

This section presents conclusions and a series of possible recommendations to improve, from a drought perspective, the water governance context in Flanders.

\subsubsection{Overall Conclusions}

The Flanders region researched in this chapter shows a limited awareness for the drought problem. By far, the most recognized problem in the region is flooding. The first actions are taken by VMM and some stakeholders, such as individual farmers, as far as agricultural droughts have been more frequent within the last decade. Thus, the VMM approach is mainly based on a scientific technocratic approach which produces modelling results to assess drought risks following the specificities of possible droughts (hydrological versus agricultural droughts or water scarcity). The estimated results are taken as basis for setting the policy agenda and development of activities. As described, Flanders takes forward a very scientific and centralized approach. The stakeholder involvement is already improving but is still limited. Measures are proposed and developed by VMM, stakeholders such as farmers, have difficulties to influence suitable solutions. Attention and regulations 
are missing at the federal level in Belgium which might be a reason why the Flemish region favours the centralized and less bottom-up approach. The Flanders level is the highest scale policy level at which the main objectives and strategies for water management are developed and at the same time the implementation of activities are covered.

The moderate supportive but partially restrictive governance setting can —if also in a limited manner - support the motivation, cognitions and resources of actors for implementing drought activities. Most actions are taken by VMM as Environmental Agency at the Flanders level which wants to push the topic but is also relying on a strong strategic vision still to be developed. Further bottom-up measures are taken by individual actors such as farmers who are installing water basins at their properties. So, motivation can be recognized partially in some actor groups. Resources are only available partially. Activities are relying on research money coming from external institutions such as the European Commission. The search for resources is taken on a case-by-case basis.

It can be summarized that Flanders is at an early stage of establishing drought resilience measures. First activities, e.g. by VMM, are starting and are initiating further motivation and processes. Water scarcity and drought is integrated in some general water management strategic documents.

\subsubsection{Increasing Awareness for Droughts}

Essential for further development of drought activities in Flanders seems to be an increase of awareness in different actor's groups, especially the groups which do not incorporate the risk in their operations. The most important audiences would be intermediaries and multipliers, such as farming associations or energy industry associations. The awareness should also be raised slowly so that in case of a drought event, at least a low media attention exists. Interviewees suggested that water pricing for actors, other than the broad public, is an important tool to increase awareness for resource scarcity. Awareness and additionally more involvement can also be increased if the flexibility to include stakeholders in the planning processes (especially selection, prioritization and calibration of measure) can be increased. Some interviewees suggested they see their involvement in current planning processes as occurring too late in the process. In other DROP case study areas (e.g. in the areas of the two Dutch pilots), authorities have had very positive experiences with strongly participatory approaches. The existing Flemish approach is focused on using models to make a scientific case for drought actions. It would seem valuable to expand VMM's strategy to include additional approaches, e.g. use of pilot measures, demonstration projects, showcasing actions, best-practice exchange schemes, and working more strongly in network-building and improving relationships with actors. Interviews showed significant potential to expand risk communication and information exchange to different economic sectors, with the objective to integrate drought risks and planning into private actors' activities. They could, 
for instance, take the form of dialogues on drought adaptation and could involve discussions on impacts and possible solutions.

\subsubsection{Mainstreaming Drought Risks and Preparedness}

With an integrated central vision for Flanders, drought management could be integrated in different environmental and related policies and could lead to a multi-objective planning of VMM but also a guidance for collaboration between Flemish Ministry of the Environment and Nature and other relevant ministries such as the Flemish agricultural ministry. Furthermore, mainstreaming into private actors' activities is missing in Flanders. Based on risk communication to private actors, the aim could be for a voluntary agreement or code of best practices for drought adaptation within and between sectors. The willingness of some actors seems to be possible. A requirement of drought contingency planning could initiate a process in the water-relevant economic sectors. Companies of these sectors could be required to prepare contingency plans for their operations during drought periods, thus increasing preparedness and reducing economic damage during drought periods.

\subsubsection{Engagement with Other Public Actors}

The relationship with other relevant authorities at the Flanders political level, e.g. with the Flemish Ministry of the Environment and Nature and the Flemish agricultural ministry could be improved by initiating further dialogues. A centralized strategic vision could also help for the cooperation with other ministries. All large Flemish rivers come from other regions. When addressing drought issues, the whole river basin should be taken into account, because Flanders is depending on activities of the upstream regions. Especially, discussions with the neighbours Germany and France should be focused. The discussion should take care of water quantity and quality. The engagement of municipalities seems to decrease; interviewees do not see it as a major problem due to the good connection between municipalities, the district and provincial level. Nevertheless, the impact of the disengagement cannot be foreseen at the moment; therefore we suggest observing the consequences this has on water management over time. Furthermore, the municipalities should be involved in the local showcases which are implemented on the ground and are also kept on board of the drought management process. 


\subsubsection{Evaluate the Importance of Data Availability Gaps and Prioritize Which to Address}

Expanding the breadth of water management to include drought issues will require making available and collecting additional data, typically needed for an adequate evaluation of measures, their prioritization and monitoring their effectiveness. VMM could take on the task of analysing data availability and identify which data gaps should be addressed and in which priority. Data regarding volumes of water abstracted and used by surface water users (and sometimes even data regarding surface water rights) is often incomplete in Northwest Europe. This kind of data can be a key to identifying where the potential for drought adaptation lies, implementing measures that make use of that potential, and enabling private actors to incorporate drought risk into their actions.

Open Access This chapter is distributed under the terms of the Creative Commons Attribution-NonCommercial 2.5 License (http://creativecommons.org/licenses/by-nc/2.5/), which permits any noncommercial use, duplication, adaptation, distribution, and reproduction in any medium or format, as long as you give appropriate credit to the original author(s) and the source, a link is provided to the Creative Commons license, and any changes made are indicated.

The images or other third party material in this chapter are included in the work's Creative Commons license, unless indicated otherwise in the credit line; if such material is not included in the work's Creative Commons license and the respective action is not permitted by statutory regulation, users will need to obtain permission from the license holder to duplicate, adapt, or reproduce the material.

\section{References}

Arnold, JG, Srinivasan R, Muttiah RS, Williams JR (1998) Large-area hydrologic modeling and assessment: Part I.Model development. J American Water Res Assoc 34(1):73-89.

Bressers H, Kuks S (eds) (2004) Integrated governance and water basin management. Conditions for regime change and sustainability. Kluwer Academic Publishers, Dordrecht

CIW (2003) Decreet betreffende het integraal waterbeleid http://codex.vlaanderen.be/Portals/ Codex/documenten/1011715.html. Accessed 3 Aug 2015

CIW (2005) De eerste waterbeleidsnota. Erembodegem

CIW (2013) Tweede waterbeleidsnota-Inclusief waterbeheerkwesties. https://www.vlaanderen. be/n1/publicaties/detail/tweede-waterbeleidsnota-inclusief-waterbeheerkwesties. Accessed 3 Aug 2015

COPERNICUS (2015) COPERNICUS global land service-Soil water index. http://land. copernicus.eu/global. Accessed 28 July 2015

EC (2000) Directive 2000/60/EC of the European Parliament and of the Council of 23 October 2000 establishing a framework for Community action in the field of water policy, p 72

EC (2007) Communication from the Commission to the European Parliament and the CouncilAddressing the challenge of water scarcity and droughts in the European Union. COM (2007) 414 final, European Commission, Brussels. http://eur-lex.europa.eu/legal-content/EN/TXT/ PDF/?uri=CELEX:52007DC0414\&from=EN. Accessed 14 Dec 2015

EC (2011) Communication from the Commission to the European Parliament the Council the European Economic and Social Committee and the Committee of the Regions A 
resource-efficient Europe-Flagship initiative of the Europe 2020 Strategy. COM (2011) 21, European Commission, Brussels, p 17

EC (2012) Communication from the Commission to the European Parliament the Council the European Economic and Social Committee and the Committee of the Regions A Blueprint to Safeguard Europe's Water Resources. COM (2012) 673 final, European Commission, Brussels, p 24

McKee TB, Doeskin NJ, Kleist J (1993) The relationship of drought frequency and duration to time scales. In: Proceedings 8th conference on applied climatology, January 17-22, 1993. American Meteorological Society, Boston, Massachusetts, pp 179-118

Vicente-Serrano SM, López-Moreno JI, Beguería S, Lorenzo-Lacruz J, Azorin-Molina C, Morán-Tejeda E (2011) Accurate computation of a streamflow drought index. J Hydrol Eng 17 (2):318-332

Vlaamse overheid (2011) Milieubeleidsplan 2011-2015. Brussel. http://www.lne.be/themas/beleid/ milieubeleidsplan/leeswijze/publicaties/Milieubeleidsplan2011-2015.pdf. Accessed 3 Aug 2015

Zreda M, Shuttleworth WJ, Zeng X, Zweck C, Desilets D, Franz T, Rosolem R (2012) COSMOS. The cosmic-ray soil moisture observing system. Hydrol Earth Syst Sci 16(11):4079-4099 